\title{
Usability Study of Smart Phone Messaging for Elderly and Low-literate Users
}

\author{
Rajibul Anam ${ }^{1}$ \\ Smartphone App Research Division \\ Anam Research \& Development Solutions \\ Dhaka, Bangladesh
}

\author{
Abdelouahab Abid ${ }^{2}$ \\ Faculty of Computer and Information Systems \\ Islamic University of Madinah \\ Madinah, Saudi Arabia
}

\begin{abstract}
Smartphones are electronic devices that people can carry around and install/add compatible third-party Apps to expend their functionality. Smartphones are mainly developed for calling and messaging purposes. All applications' interfaces are designed for the current trends. Therefore, Senior Citizen and Low-literate users face difficulties to use smartphones due to the perceived complicated interface and functionality. This paper analyzes Senior Citizen and Low-literate user's requirements to read and write messages from users "memory load", "navigation consistency", "consistency and standard", and "touch screen finger-based tapping" perspective. Then a framework based on "visual representation", "navigation" and "miss click avoidance" is developed. A comparison between the proposed application and other messaging applications is provided. This research work focused on the Senior Citizen and Low-literate users to improve their user experience of the smartphone messaging application.
\end{abstract}

Keywords-Smartphone interface; smartphone messaging; visual color; adaptation

\section{INTRODUCTION}

The smartphone is a device that runs by its own independent operating system, supports touchscreen functionality, very small in size, has calling functionality, can install third-party applications and can carry anywhere [1]. The cell phone was developed only for calling purpose but due to the smartphone with modern technology, it becomes very popular to use and can run much application simultaneously [2]. The smartphone applications are developing very rapidly, with these applications users can make phone calls, reminders, planning, internet calls, online message, sending emails, banking operations, games, etc. [3]. Recently the wearable technology becomes very popular with the young generation [4]. Everyday a variety types of the smartphone are introducing in the market by different companies and each manufacturing companies has its own different functionalities [5]. The user interface should follow a pattern to serve the diversity of the application. An application should be accessed by as many people as possible with the maximum range of environment [6]. Mobile user interface design is not as easy as a desktop app interface design. The functionalities of some mobile devices are very easy for some users and at the same time, it is very hard to understand [7].

Around the globe, five billion people are using mobile services [8]. Among these users, most of them are young and have advanced knowledge of technology. According to the
World Health Organization, the world's population will cross two billion who's age is sixty over by 2020 [8], [9]. Among them, those who are over eighty years having movement and motor problems, moreover some users having motor problems after fifty years [10-11]. Most of these Elderly and Low-literate users do not use the smartphone. The main barrier is the usability, short term memory and technology adaptation phobia [12-15]. The usability refers to user satisfaction, how effective and efficient way to complete the task with the given interface with less error [5], [16]. Because smartphone is equipped with touchscreen instead of button keypad [6], limited screen size 3.2" up to 12.9" [17], poorly design for the senior adults which is very hard to adapt [18-19], icons are very small in size [2021], text entry which refers to incorrect input [18], [22], inconsistence navigation to go next page or previous page [7], [23], and hand/motor function is slow compared to the younger user which required touch operation [24-25]. The mobile manufacturing companies are developing mobile layout according to the trend to do commercialized their product. No one is considering the Elderly Citizens, what interface will give them comfort to use the device [26]. As a result, there is a big number of people in our society who are Elderly and try to avoid using smartphones [27-29]. Some researchers think that the next generation of Elderly citizens will be different from the Current Generation of Elderly citizens. This Generation is habitual with the present system and when they become Elderly Citizen will be easy for them to use the smartphone [30]. But still, they will have to face cognitive and motor function issues [24].

Most of the Elderly Citizen uses the Button Phone, which is called non-smartphone [28]. Because of the advanced technology most smartphone users use third-party apps to communicate with each other [2]. The Elderly and Low-literate users use the smartphone only to communicate with their grandchildren and family members through third-party apps including Facebook, WhatsApp, Tumblr, Instagram, WeChat and Twitter [17], [31-32]. There is a big gap in usability between non-smartphones and smartphones. This paper proposes a system where tries to resolve the gap between using the non-smartphone to the smartphone.

This paper is arranged as follows. Section 2 provides a brief review of other Smart Phone System, which is made for Elderly and Low-literate users, Section 3 describes the proposed solution, Section 4 details discussion, and results of the proposed methods and finally, the conclusion is in Section 5. 


\section{RELATED WORKS}

Usability is based on Learnability, Efficiency, Memorability, Satisfaction, and Errors [5]. The Heuristic Evaluation is a set of usability principles, which has evaluated by the experts and collects a list of usability problems [16].

\section{A. Usability}

Smart Phone Accessibility Testing and Evaluation focus on the WCAG 2.0 best practice. Author in [17] research focus on the app Interface labels, fonts, colors, and buttons size, moreover on the consistency of the navigation. The Usability study focuses on five social networking apps including Facebook, Tumblr, WhatsApp, Twitter and Instagram. The research found that most of the apps do not follow the color guideline and very poor readability. The Multimedia contents navigations are not in the proper place to interact with. The usability test shows that non-experienced Elderly participants face problems to navigate and finish the specific task on time.

Mobile Health System is a standalone application for the elder and low literate users. Author in [33] design interface (UX) for Glucose Measurement application prototype followed the guideline of UU principle which is under mobile health guidelines and the development tool named Balsamiq and also did usability study on Elderly people who are over fifty years older. The usability study was done by ten specific tasks with Control and Experimental Group of People. The Experimental Group performance was better than the Control Group. This study focus on user preference design, options they prefer to use. This study does not focus on multimedia content.

Mobile user's behavior and UX design make the user's satisfaction level high. Author in [5] followed the standard life cycle of usability testing. The usability test conducted by six types of tasks which is related to the multimedia contents and each task contains six types of instructions with five participants. The tasks asked the Elderly users to use a web browser, calendar and image gallery. After finished the testing the participants give feedback that application navigation and options are not clearly visible on the screen.

Multi-Touch Mobile App Interface is a vital issue for the Elderly and Low-literate users. Author in [12] put focus on the Age-Related Changes, Suitable Input at different model devices, Multitouch Interface users and Designing of Multitouch Interfaces for Elderly. After analyzing these issues, create an initial design guideline for the app development to Target the Interface Design, Use of Graphics, Navigation and Errors, Content Layout Design, User Cognitive Design, Audio, Text Design, User Feedback and Support, Multi-Touch Interaction and Interface Testing. The design guideline was created with structure, in detail and very comprehensive which overcome the age-related changes which might create impact the usability of the multi-touch interface.

Aging is a process of losing physical and cognitive abilities over time. Author in [34] worked on the human coming age, touch interfaces and developed a framework for how touch screen suites Elderly. The researchers collect Elderly user's Smartphone Experience data, touch the interface action activities, look and feel about the buttons, functions they use most. The users feel comfort interface like TV remote control type buttons. At the experiment time found human errors to register the actions like button press pointing position was wrong. They proposed a framework consist of four factors tangible manipulation, spatial interaction, embodied facilitation and expressive representation. The big factor of designing the apps on the assumption of a group, they are sometimes not able to see what the small screen is requesting, which button needs to press and how long or how hard it needs to press the area of the button.

\section{B. Heuristic Evaluation}

There are many User Interface has been developed for the Elderly and Low-literate users but most of the designs are rejected by the Usability Study. Author in [1] tried to identify the major usability problems while interacting with the mobile. To improve the User Interface, they proposed a heuristic framework named SMASH which is consists of twelve usability cases. There were five experts involved in this evaluation. The study shows that twenty-seven heuristic violations encountered. The violations were to "Minimized the user's memory load" and "match between system and realworld". The usability problems are classified into four groups as appearance, language, dialogue and information. This study shows some critical points which need to improve for better Elderly and Low-literate user experience.

Author in [16] Heuristic Evaluation is organized in two stages, one is validation regarding traditional heuristics and another one is validation regarding outcomes from the test with real users. The test was run by the Aptor Software, the application is developed for the Brazilian Elderly people. The Heuristic results show that fourteen factors are not following the rules and nine usability problems countered at the testing period. So, the experts provide a guideline to the developers to make the app more interactive for the Elderly.

Mobile Learning for the Elderly and Low-literate users' is vital to the present days. Author in [8] developed mobile learning applications to overcome the accessibility issues in order to maximize the usage of the smartphone by Elderly. At the testing period, they found certain accessibility issues for the Elderly. The study was conducted with thirty-two scenarios in a controlled environment. The results come up with certain errors and the experts create a guideline for the smartphone application developers which will help them to makes the application interactive for the Elderly.

Six Smartphone Launchers were introduced for the Elderly and did Heuristic evaluation [11]. The evaluation was classified into three categories firstly look and feel, secondly interaction and lastly functionality. Look and Feel followed by twenty-one criteria, interaction procedure followed by fifteen criteria and functionality followed by thirteen criteria. The evaluation result shows that thirty-nine percent problem list out and sixty-one percent with no problem. The problem listed from three classifications. The results help the future smartphone launcher developers to make an interactive app for the Elderly. 


\section{UNDERSTANDING THE ISSUES AND COLLECT REQUIREMENTS}

\section{A. Types of Senior Citizen}

Senior Citizen or Elderly is defined those are aged sixty and above [18]. But still, there are different types of Elderly exist in our society according to their ability.

1) Fit older people: Elderly who are fit to do most of the work and physical functionalities what they want to do but activities are different from while they were younger [6], [35].

2) Frail older people: Elderly who are fit with some disabilities and having some problem to do regular physical activities [6], [35].

3) Disable person: Who Grow Older Elderly having long term physical disabilities and affected by the aging moreover dependent on their own physical functionalities [6], [35].

The Elderly face problem to understand vision, hearing, dexterities, understanding the menu and navigation links, social contact and mobile application infrastructure [1], [6].

\section{B. User's Memory Load}

Aging creates memory problems which may start from mid-level of age, memory loss makes human forgetting names, phone numbers, moving objects from one place to another [9]. The smartphone user interface should provide objects which are visible (make elements easy to read), options (easy to accessibility and recognition) and actions (make clickable items easy to target and hit) to prevent irrelevant information from user memory [1], [16], [23]. The menu path should be easy to remember [14].

\section{Navigation Consistency}

Navigation is very important to complete a task effectively and efficiently [1]. The navigation should be consistent and straightforward [7], [23]. Navigation becomes very important when the system is used by the Elderly. Most of the time Elderly open apps and face problem to go back to previous state or face problem to close the app [1], [17], [11], [36], one application put the back button at the top of the page and another app put the back button at the bottom of the page [1], [11]. The back button should be the same place on every screen [17], [31]. The back button should navigate back one level each time [7]. Menu navigation is another factor that makes the Elderly and Low-literate users confused most of the time [6]. The menu is implemented at top of the page by one app and another app puts the menu at the left or right of the page [6]. The app menu should be consistent so the user can access it very easily.

\section{Consistency and Standard}

The smartphone user interface should be comforting to do a task in a familiar, standard and consistent manner [1]. The labels and buttons are not marked correctly and not large enough to initiate or interact with [16-17], [31], font size and spacing is not consistence and appropriate [9], [11], [13-14], [16-17], icon size is small to read and icon symbol is not familiar [9], [12], [15-17], [20], objects color reflection and contrast is not visible (visual acuity) and does not fulfill the readability for the Elderly [6], [11-13], [17], [37]. Displaying content information of the apps sometimes creates confusion, there are different methods to display contents like vertical list, thumbnail list, fisheye list, carousel, grid and film stripe [6], [11].

\section{E. Touch Screen Finger based Tapping}

Motor, cognitive, and physical abilities make a person perceive and process information [6]. Button design is one of the most common elements on all platforms. There are two types of touch screen, first one is Resistive Touch and second is Capacitive Touch Screen, there is no difference at user end functional difference, these two are hardware issues [38]. There are many types of buttons in mobile applications like action button, radio button, list button, text button, toggle button, icon action button and floating action button [6]. Small size button requires standard human motor control, different timing of contact on buttons may alter the actions. Moreover, it is more complex when it is about to design a button or icon to serve a specific purpose [6], [12], [34]. There are two types of touch interaction supported by smartphones, the first one is a single touch and the second one is multi-touch [39]. Smartphone usability measurement is different because touch screen allows direct interaction using fingers to register a button press by objects (button text and icon), moreover smaller object leads to finger occlusion and wrong point of the press [6], [11], [14], [40]. The Elderly always target to press the target button but due to motor problem, they press outside of the target object and press the target object more or less time it needs to register the request [7], [14], [18], [25], [40-41].

\section{DESIGN AND DEVELOPMENT}

There are two types of design issue named functional and nonfunctional, which can improve the usability for the Elderly and Low-literate users.

\section{A. Functional}

The functional design specifies a function that the system component must be able to do in a discrete manner. In other words, functionality is describing the behavior of the system [7].

\section{B. Nonfunctional}

The nonfunctional design is related to usability, performance, acceptance, reliability, quality, effectiveness. In other words, nonfunctionally is an overall property of the system of a particular aspect which is not a specific function [7].

\section{Visual Representation}

Visual representation is a very important factor for touch screen devices, firstly the vision, which gives a clear message to the user, secondly the visual buttons input boundaries which work as button press and finally the text input boundaries should be large enough to give input [7]. The page title fonts size needs to be big and background color should be highlighted with green or blue color [15-17], [31] and same time needs to add an illustration to represent the meaning so the Low-literate users will get a clear idea of the page.

1) Title and illustration of the page: Every page contains its basic information like the name of the page, so the user can 
easily trace down where or which place they are in. Fig. 1 shows the Google Messages [42] Inbox page, this stage user does not know which page they are now. Fig. 1(a) shows only the Application name, if the user is Elderly or Low-literate user then might face problem to understand the purpose of the page, (b) shows the unread received messages and (c) shows the read received messages. The unread messages are dark black in color and read messages are dim black in color. For the Elderly or Low-literate users, this design is not appropriate. Fig. 2(a) clearly represents the INBOX by illustration and name. The title background color is Green and the font color is white, which will give a clear view of the content. The inbox title gives the idea of the page and the illustration gives a clear idea of the page to the Elderly and Low-literate users, (b) Status notify the users to weather the user previously read the message or not. If the user opens it once the status will be Blue in color and not opened then the status color will be Red and text will be Not Read at white background, (c) provides the message received time. It provides message received hourly and day information exactly bottom of the message summary, finally (d) provides the message summary, maximum three lines will be shown here, for a clear view of the content, the background color used as white and font color Dark Green. Fig. 3 shows the Inbox Display algorithm, where line 1-3 uses the messageobject to check and update the status of the message status, line 4 get the mobile screensize and totalmessagesize value. The screensize get the mobile screen dimension value (different mobile different screen sizes) and totalmessagesize count the number of characters in the message body. Line 6 converts the screensize and totalmessagesize to pixels and line 7 assign the summerymessage as part of the text message which will fit within 3 lines according to the mobile screen dimensions.

2) Arrange distance between objects: Elderly and Lowliterate users are not familiar with the technology. Fig. 4 shows the Google New Message page, where (a) shows the gap between two objects, (b) input recipient number and (c) input text message. The input recipient number (b) and (c) input text message height is very small and will create human error to touch the specific points. Moreover, the distance between two objects (b) and (c) is long, which might make the users confused.

The proposed solution Fig. 5 shows the minimal distance from one object to another according to the user prospect, (a) shows the distance between the recipient name and message body, (b) shows the distance between two messages and in the middle there is a thin line which makes them separate. The status notification (c) shows message status with reading, not read and time of receiving. Fig. 6 shows the New Message page, where (a) shows the minimum distance from the recipient's name and text message input boxes, (b) shows the thin borderline outside of the input objects. So, the users can easily understand where they have to press their fingers to register an action.

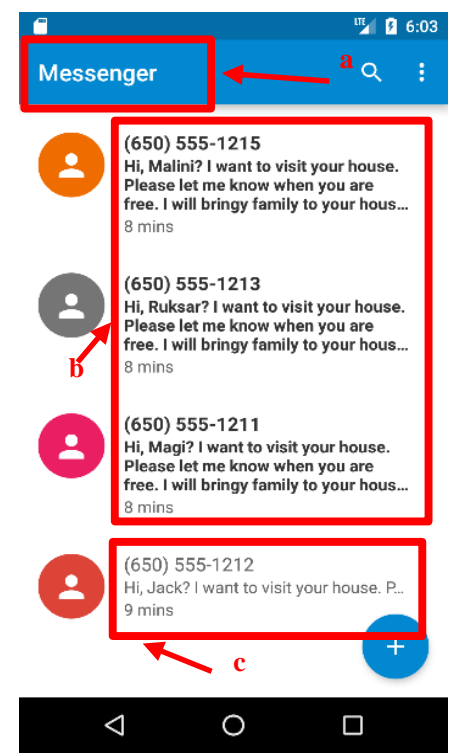

Fig. 1. Google Message Inbox.

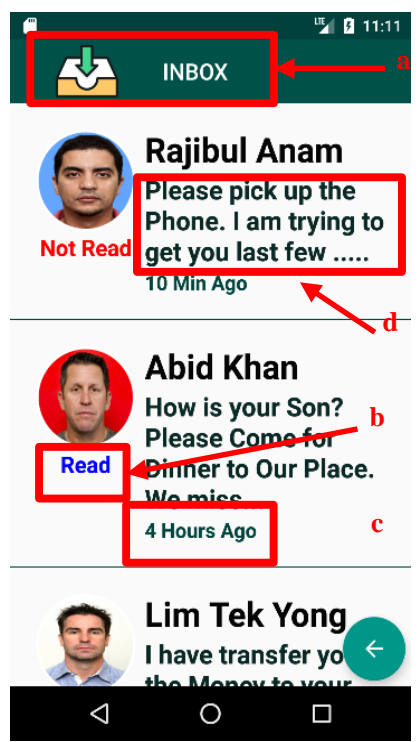

Fig. 2. Proposed Message Inbox.

\begin{tabular}{|ll|}
\hline Input: & messageobject is the total message contents; \\
Output: & summerymessage is the total message contents; \\
Variables: & screensize is the mobile screen size; \\
& \\
InboxDisplay (messageobject) \\
1. & If messageobject is open once Then \\
$\mathbf{2 .}$ & messageobject status is Read; \\
3. & Else messageobject status is Not Read; \\
4. & Calculate screensize and totalmessagesize \\
5. & Do \\
6. & Get screensize pixels and threeline pixels; \\
7. & Assign summerymessage content maximum three line of \\
8. & textmessage; \\
\hline
\end{tabular}

Fig. 3. Inbox Display Method. 


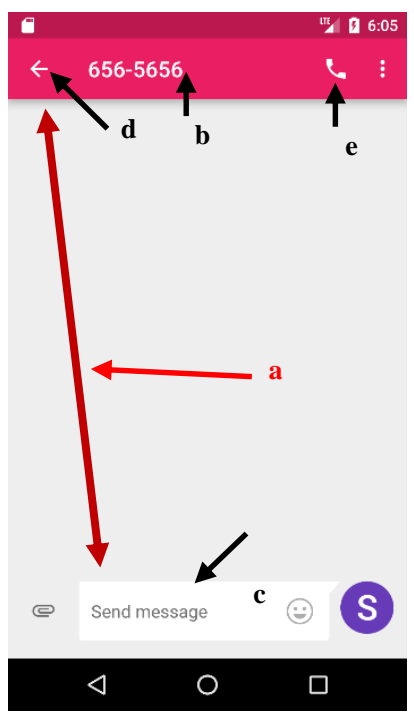

Fig. 4. Google Write New Message.

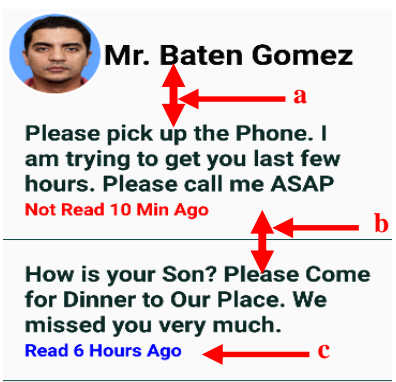

Fig. 5. Distance between Objects.

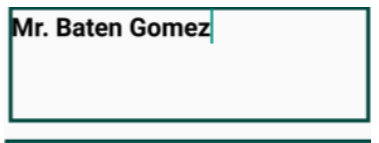

Type New Message

Fig. 6. Border at Input Objects.

\section{Navigation}

The navigation and menu are major factors to operate any application moreover, the Elderly and Low-literate users face problems to use smartphone regular menu because of their mental model, most of them are familiar with the linear menu style instead of the hierarchical menu [7]. The navigation links visual text and color needs to be very clear to the users after click which page will appear to the user and how to return back to the main page these issues need to be very clear in the navigation.

1) Floating navigation: Fig. 1 is the Inbox screenshots, there is no back button and Fig. 4(d) has back navigation, from these both pages it is visible that back navigation is not consistent. There is back navigation at all the pages, Fig. 7, 8(a) shows the back-navigation button which is consistence at the right bottom of the page. The proposed system Fig. 7, 8(b) design in a manner so the most important navigation action stands the left bottom of each page. Fig. 7 is the inbox page, where reply navigation is the most important action (b), same way Fig. 8 is the New Message Page and Send navigation is the most important action (b). This design will help the Elderly and Low-literacy users to avoid human error and confusion. Fig. 9 illustrates the Previous State method, where the session keeps all the state information of the application, line 2 previoussession get the previous state information and line 3 return the previous state information.

2) Button navigation: The button is the basic action mechanism to register an action. Fig. 4(e) shows the google message system button to add the message recipient's name. The "add message" recipients button symbol is not clear for the Elderly and Low-literate users moreover, there is no text information in the button. So, users might get confused about how to add new recipient's names. Fig. 8(c) shows the proposed add message recipient button, where the background color is white and the symbol is in blue color, the button has white space around it so the users will have a clear vision of the button. The proposed method will reduce human error and confusion.

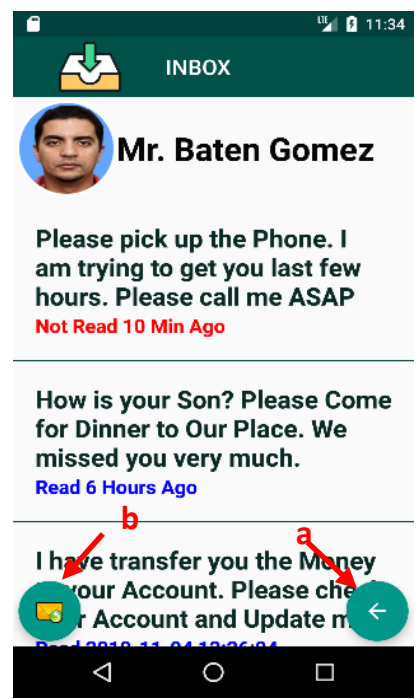

Fig. 7. Floating Navigation.

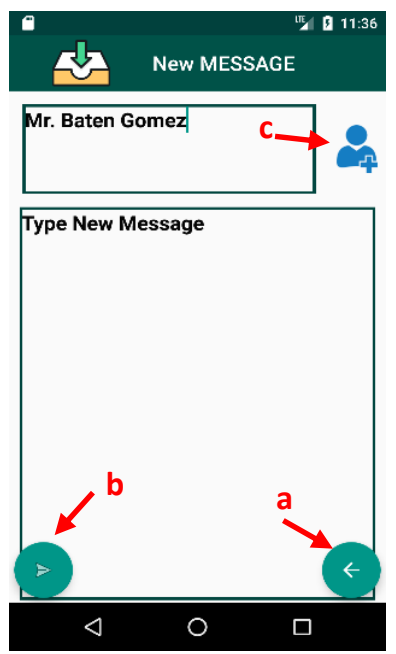

Fig. 8. Button Navigation. 


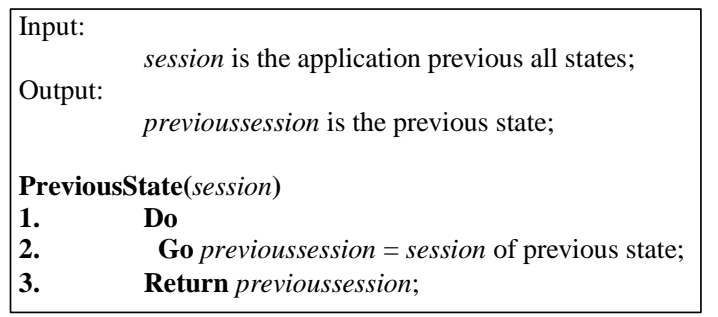

Fig. 9. Previous State Method.

\section{E. Miss Click Avoidance}

Miss click is one of the common mistakes and most of the time made by the Elderly and Low-literate users. Clicking on the interface or button requires a long press to register an action [7]. But most of the time users failed to register the action because of the proper way of pressing to the action point or shake the fingers at pressing time.

1) Action button register with additional space: To avoid the missing click of the target button, proposed additional space button design which will help the Elderly and Lowliterate users to perform task smoothly. Fig. 10(a,b) shows the navigation button, both the navigation button is rounded by the red circle. Basically, the button press action gets register only when the user press exactly inside the button, but for the Elderly and Low-literate users, proposed a button which will work 5px radius outside of the button to register an action. Fig. 10(a,b) both buttons radius increase and action points work till the red circle radius, these $5 \mathrm{px}$ radius is invisible boundaries to the users but at action time it will work to register an action. Fig. 11(a) shows the add recipients button, the button size is small which might create a miss click of the button, so add 5px each of the button so the action button gets register very easily Fig. 11(a) red square shape.

2) Multiple and finger shake press: Most of the time Elderly and Low-literate users do not prefer to use a smartphone because they face problems interacting with the apps and the main reason they comply is multi-touch issues. As a result, they failed to register the action of the button. So, to overcome this issue proposed a method, where the user might do 2multi-tap to the action button or tap and shake finger while taped the button, the system will register the action as a single tap. Fig. 12 shows the Action Register Method, where line 1 and 2 check the button action register single tap or multiple tap or finger shake taped then the system will register the action as single tap, line 3 check the action button input boundary, if the action button is normal button, then line 4 add extra 5px (five pixels) all side of the button, as a result, the button action register capacity increase and user can register the actions very easily.

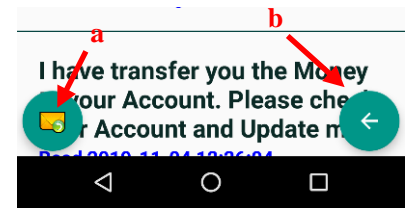

Fig. 10. Button Touch Action Points.

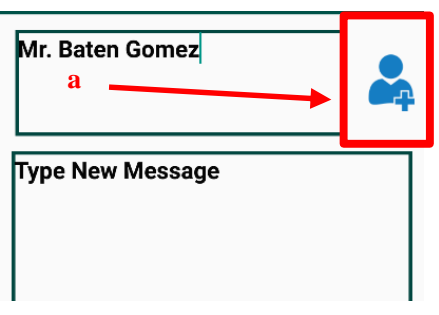

Fig. 11. Object Action Points.

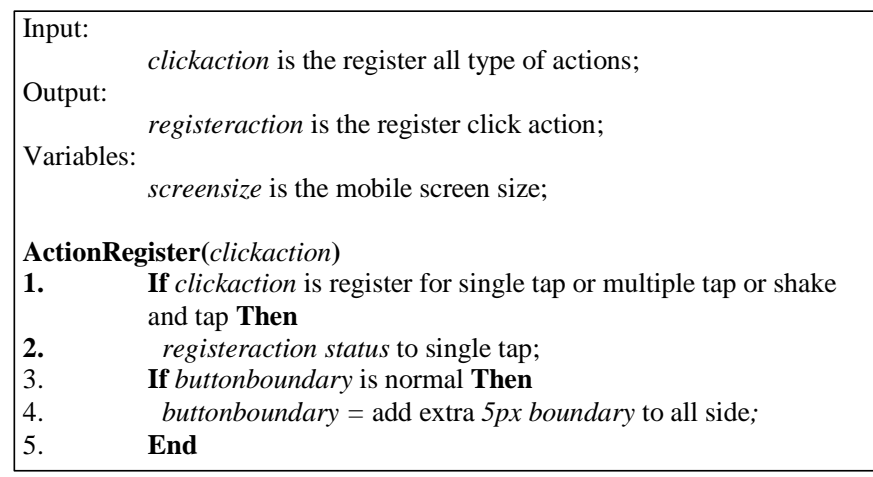

Fig. 12. Action Register Method.

\section{RESULTS AND DISCUSSION}

Smart Phone User Interface designing is not easy for the Elderly and Low-literate users. There are many types of Smart Phone Platform is in the market like Android, iOS, Tizen, Sailfish OS, Windows, BlackBerry, Firefox OS, etc. [43]. This research has done on the Android Platform. There are many Android Messaging Applications in the Android Play Store but only a few applications are for the Elderly and Low-literate users. Table I illustrates four types of message apps first one is Google Messages [42], Raku-Raku [25], Big SMS [44] and Large Launcher [45]. Among these apps, only Google Messages [42] is open source app and all four applications are platform-dependent, which means can run only in Android and these apps are specially designed for the Elderly, moreover none of these apps are designed for the Low-literate users.

Every Smart Phone has a Message System. Table II shows the functionality of the Elderly which enhances the user experience. Multiple Tap is a critical issue to register an action. Only Raku-Raku [25] and Proposed System do not support Multiple Tap. Only Google Messages [42] is not designed for the Elderly and other apps are designed for the Elderly. Google Messages [42] and Proposed System has Navigation Consistency. The other three apps do not follow navigation consistency. Clear and Big Icons are used only in Big SMS [44] and Proposed System, other systems they use different size and color icons. Elderly and Low-literate users most of the time face problems to identify the action buttons. The Big SMS [44] system does not highlight on the button objects. The Back Button is not consistent in all the systems. Some Systems show back navigation in one page and other pages they do not have the navigations. The only proposed system continuously follows the Back Button Navigation on every page. Raku-Raku [25] and Proposed system use an algorithm to register an action to avoid miss clicks, other systems use a basic algorithm to register an action. 
The time complexity depends on the flow of the algorithm. The algorithm complexity gets higher if it uses any nested operation [46]. Table III shows the comparison of the Proposed and Google Messages System [42], where $O$ denotes the growth of a function and $n$ is the number of steps. The Register Button Action Method, Display Message Method and Return to Previous State Method growth and time complexity are almost the same between two systems, but there are differences in the execution time because of the dependency, which related to the interaction methods and object response time.

TABLE. I. COMPARISON OF MESSAGE SYSTEM CRITERIA

\begin{tabular}{|l|l|l|l|l|}
\hline & $\begin{array}{l}\text { Google } \\
\text { Messages [42] }\end{array}$ & $\begin{array}{l}\text { Raku- } \\
\text { Raku [25] }\end{array}$ & $\begin{array}{l}\text { Big } \\
\text { SMS } \\
{[\text { 44] }}\end{array}$ & $\begin{array}{l}\text { Large } \\
\text { Launcher [45] }\end{array}$ \\
\hline Open Source & Yes & No & No & No \\
\hline $\begin{array}{l}\text { App code } \\
\text { Required }\end{array}$ & Yes & Yes & Yes & Yes \\
\hline $\begin{array}{l}\text { Platform } \\
\text { Dependent }\end{array}$ & Yes & Yes & Yes & Yes \\
\hline $\begin{array}{l}\text { Support } \\
\text { Elderly Users }\end{array}$ & Yes & Yes & Yes & Yes \\
\hline $\begin{array}{l}\text { Support Low } \\
\text { Literate } \\
\text { Users }\end{array}$ & No & No & No & No \\
\hline
\end{tabular}

TABLE. II. COMPARISON OF MESSAGE SYSTEM USER INTERFACE AND FUNCTIONALITY

\begin{tabular}{|l|l|l|l|l|l|}
\hline Criteria & $\begin{array}{l}\text { Google } \\
\text { Messages } \\
{[\mathbf{4 2}]}\end{array}$ & $\begin{array}{l}\text { Raku- } \\
\text { Raku } \\
{[\mathbf{2 5}]}\end{array}$ & $\begin{array}{l}\text { Big } \\
\text { SMS } \\
{[\mathbf{4 4}]}\end{array}$ & $\begin{array}{l}\text { Large } \\
\text { Launcher } \\
{[\mathbf{4 5}]}\end{array}$ & $\begin{array}{l}\text { Proposed } \\
\text { System }\end{array}$ \\
\hline $\begin{array}{l}\text { Support Multi } \\
\text { Tap }\end{array}$ & Yes & No & Yes & Yes & No \\
\hline $\begin{array}{l}\text { Design UI for } \\
\text { Elderly }\end{array}$ & No & Yes & Yes & Yes & Yes \\
\hline $\begin{array}{l}\text { Navigation } \\
\text { Consistency }\end{array}$ & Yes & No & No & No & Yes \\
\hline $\begin{array}{l}\text { Clear Navigation } \\
\text { Icon }\end{array}$ & No & No & Yes & No & Yes \\
\hline $\begin{array}{l}\text { Button Objects } \\
\text { easy to identify }\end{array}$ & Yes & Yes & No & Yes & Yes \\
\hline $\begin{array}{l}\text { Previous State } \\
\text { Navigation } \\
\text { consistency }\end{array}$ & No & No & No & No & Yes \\
\hline $\begin{array}{l}\text { Algorithm to } \\
\text { Register Action to } \\
\text { Avoid Miss Clicks }\end{array}$ & No & Yes & No & No & Yes \\
\hline
\end{tabular}

TABLE. III. COMPLEXITY OF THE ALGORITHMS

\begin{tabular}{|l|l|l|}
\hline & $\begin{array}{l}\text { Time Complexity of } \\
\text { Google Messages [42] }\end{array}$ & $\begin{array}{l}\text { Time Complexity of } \\
\text { Proposed System }\end{array}$ \\
\hline $\begin{array}{l}\text { Register Button } \\
\text { Action Method }\end{array}$ & $O(n)$ & $O(n)$ \\
\hline $\begin{array}{l}\text { Display Message } \\
\text { Method }\end{array}$ & $O(n)$ & $O(n)$ \\
\hline $\begin{array}{l}\text { Return to Previous } \\
\text { State Method }\end{array}$ & $O(n)$ & $O(n)$ \\
\hline
\end{tabular}

\section{CONCLUSION}

Respected Elderly and Low-literate people in society become a concern for government officials all over the world. Everyone is focusing on quality aged care and smooth communication among them to minimize the gap between the Elderly and the Present era. For better communication and interaction now days Smart Phone is the best device to work on. But all the smartphone is designed with the present trends. So, the Smart Phone trends work on the youth but when it goes to the Elderly and Low-literate users then they can see phobia or biasness is working on their mind. These groups of people scare to use the Smart Phone because of the interface and interaction methods.

Based on the research work, this paper developed a Smart Phone Messaging System only for the Elderly and Low-literate User's needs. This system focuses on the User Interface, Human and Smart Phone Interaction to enhance the usability and better Elderly and Low-literate User Experience. The proposed system is compared with other systems. The proposed system will fulfill the Elderly and Low-literate User needs, which will minimize the phobia and biasness.

A large scale of work has been carried out for the Elderly and Low-literate users. Still, the usability testing and evaluation must take place for the next step. After usability evaluation maybe more functionality or features need to be added or removed. So, the next step will do usability evaluation by the Elderly and Low-literate user and after getting the results, update the system, release it to the general public.

\section{REFERENCES}

[1] H. M. Salman , W. F. W. Ahmad, and S. Sulaiman, "Usability Evaluation of the Smartphone User Interface in Supporting Elderly Users From Experts' Perspective", IEEE Access, vol. 6, pp. 22578 22591,2018

[2] R. A. A. B. R. A.. Razak, and R. Cagadas, "Usage, Trend, Attitude, Likes and Dislikes of Elderly on New Technology Smartphone", Qualitative and Quantitative Research Review, vol. 3, no. 1, pp. 183 211, 2018.

[3] F. Özsungur, and O. Hazer, "Analysis of the Acceptance of Communication Technologies by Technology Acceptance Model of the Elderly: Example of Adana Province", International Journal of Eurasia Social Sciences, vol. 9, no. 31, pp. 238 - 275, 2018.

[4] C.A.L. Valk, Y. Lu, Mirana Randriambelonoro, and Jari Jessen, "Designing for technology acceptance of wearable and mobile technologies for senior citizen users", Academic Design Management Conference Proceedings (ADMC 2018), pp. 1361-1373, 2018.

[5] S. Sajjad, D. M. Khan, N. Saher, and F. Shahzad, "The Usability Analysis of Mobile Interfaces", Science International(Lahore),vol. 28, no. 2, 2016.

[6] L. Punchoojit, and N. Hongwarittorrn, "Usability Studies on Mobile User Interface Design Patterns: A Systematic Literature Review", Advances in Human-Computer Interaction, vol. 2017, pp. 1 - 22, 2017.

[7] C. Kyfonidis, and K. Renaud, "A Mobile Interface for the Older User", Proceedings of BCS Health Informatics Scotland 2016 Conference, pp. $1-9,2016$.

[8] C. D. de Oliveira, M. L. Fioravanti, R. P. de M. Fortes, and E. F. Barbosa, "Accessibility in mobile applications for elderly users: a systematic mapping", 48th Annual Frontiers in Education Conference (FIE 2018), pp. 172-180, 2018.

[9] C. Goumopoulos, I. Papa, and A. Stavrianos, "Development and Evaluation of a Mobile Application Suite for Enhancing the Social Inclusion and Well-Being of Seniors", vol. 4, no. 3, pp. 1-27, 2017. 
[10] J. R. T. Araújo, R. R. T. Lima, I. M. Ferreira-Bendassolli, and K. C. de Lima, "Functional, nutritional and social factors associated with mobility limitations in the elderly: a systematic review", Salud Pública de México, vol. 5, no. 5, pp. 579-585, 2018.

[11] M. S. Al-Razgan, H. S. Al-Khalifa, and M. D. Al-Shahrani, "Heuristics for Evaluating the Usability of Mobile Launchers for Elderly People", International Conference of Design, User Experience, and Usability, pp. 415-424, 2014.

[12] B. Loureiro, and R. Rodrigues, "Design Guidelines and Design Recommendations of Multi-Touch Interfaces for Elders", The Seventh International Conference on Advances in Computer-Human Interactions, pp. 41- 47, 2014.

[13] S. K. Goel , N. Haryani , P. Tiwari, A. Jain , and P. Kuvalekar, "Smart Phone for Elderly Populace", International Journal of Research in Engineering and Technology, vol. 2, no. 10, pp. 33-35, 2013.

[14] T. van Dyk, H. Gelderblom, K. Renaud, J. van Biljon, "Mobile Phones for the Elderly: a design framework", International Development Informatics Association Conference, pp. 85-102, 2013.

[15] M. Pino, C. Granata, G. Legouverneur, M. Boulay, and A-S. Rigaud, "Assessing design features of a graphical user interface for a social assistive robot for older adults with cognitive impairment", Gerontechnology, vol. 11, no. 2, 2012.

[16] A. de L. Salgado, L. A. do AmaralRenata, P. de M. Fortes, M. H. N. Chagas, and G. Joyce, "Addressing Mobile Usability and Elderly Users: Validating Contextualized Heuristics", International Conference of Design, User Experience, and Usability, pp. 379-394, 2017.

[17] A. Hafez, Y. (Kathy) Wang, and J. Arfaa, "An Accessibility Evaluation of Social Media through Mobile Device for Elderly", Proceedings Advances in Intelligent Systems and Computing, vol. 607, pp. 179-188, 2017.

[18] D. Williams, M. A. U. Alam, S. I. Ahamed, and W.. Chu, "Considerations in Designing Human-Computer Interfaces for Elderly People", International Conference on Quality Software, pp. 372-377, 2013.

[19] H. B. Duh ,E. Y. Do, M. Billinghurst, F. Quek, V. H. Chen, "Seniorfriendly technologies: interaction design for senior users", Proceeding CHI '10 Extended Abstracts on Human Factors in Computing Systems, pp. 4513-4516, 2010.

[20] R. Leunga, J. McGrenere, and P. Graf, "Age-related differences in the initial usability of mobile device icons", Journal Behaviour \& Information Technology, vol. 30, no. 5, pp. 629-642, 2011.

[21] W. Qian, and W. WenDao, "Interface Design of Handheld Mobile Devices for the Older Users", International Conference on e-Education, e-Business, e-Management and e-Learning, vol. 27, pp. 185-188. 2012.

[22] I. Medhi, S. Patnaik, E. Brunskill, S.N. N. Gautama, W. Thies, and K. Toyama, "Designing mobile interfaces for novice and low-literacy users", ACM Transactions on Computer-Human Interaction, vol. 18, no. 2, 2011.

[23] J. Manuel, Dí. Bossini, and L. Moreno, "Accessibility to mobile interfaces for older people", International Conference on Software Development and Technologies for Enhancing Accessibility and Fighting Info-exclusion, pp. 57-66, 2013.

[24] M. Pattison, and A. Stedmon, "Inclusive design and human factors: designing mobile phones for older users", PsychNology Journal, vol. 4, no. 3, pp. 267-284, 2006.

[25] K. Furuki, and Y. Kikuchi, "Approach to Commer ialization of RakuRaku Smart Phone", Fujitsu Sci. Tech, vol. 49, no. 2, 2013.

[26] K. Renaud, R. Blignaut, and I. Venter, "Designing Mobile Phone Interfaces for Age Diversity in South Africa: "One-World" versus Diverse "Islands"", IFIP Conference on Human-Computer Interaction, pp. 1-17, 2013.

[27] N. Charness, M. Dunlop, C. Munteanu, E. Nicol, A. Oulasvirta, X. Ren, S. Sarcar, and C. Silpasuwanchai, "Rethinking Mobile Interfaces for Older Adults", Proceedings of the 2016 CHI Conference Extended Abstracts on Human Factors in Computing Systems, pp. 1131-1134, 2016.
[28] J. Gao, and A. Koronios, "Mobile Application Development for Senior Citizens", Pacific Asia Conference on Information Systems, pp. 214225,2010

[29] E. Lindh, and A. John, "Designing IT for Older People", In: Exploiting the Knowledge Economy: Issues, Applications and Case Studies, PTS 1 AND 2, IOS Press, pp. 1523-1530, 2006.

[30] B. Aguiar, and R. Macário, "The need for an Elderly centred mobility policy", Transportation Research Procedia, vol. 25, pp. 4355-4369, 2017.

[31] B. W. Kiat, and W.. Chen, "Mobile Instant Messaging for the Elderly", 6th International Conference on Software Development and Technologies for Enhancing Accessibility and Fighting Infoexclusion, pp. 28-37, 2015.

[32] K. Chen, Alan H. S. Chan, and S. N. H. Tsang, "Usage of Mobile Phones amongst Elderly People in Hong Kong", Proceedings of the International MultiConference of Engineers and Computer Scientists, vol. 2, 2013.

[33] K. Kalimullah, and D. Sushmitha, "Influence of Design Elements in Mobile Applications on User Experience of Elderly People", International Conference on Current and Future Trends of Information and Communication Technologies in Healthcare (ICTH 2017), pp. 352359. 2017.

[34] A. L. Culén, and T. Bratteteig, "Touch-Screens and Elderly users: A Perfect Match?", The Sixth International Conference on Advances in Computer-Human Interactions, pp. 460-465, 2013.

[35] M. Faisal, M. Yusof, N. Romli, M. F. M. Yusof, "Design for Elderly Friendly: Mobile Phone Application and Design that Suitable for Elderly", International Journal of Computer Applications, vol. 95, no. 3, 2014.

[36] A. Britton, R. Setchi, and A. Marsh, "Intuitive interaction with multifunctional mobile interfaces", Journal of King Saud University Computer and Information Sciences, vol. 25, pp. 187-196, 2013.

[37] A. Holzinger, G. Searle, and A. Nischelwitzer, "On Some Aspects of Improving Mobile Applications for the Elderly", International Conference on Universal Access in Human-Computer Interaction, pp. 923-932, 2007.

[38] S Sharma, P. Singh, R. Sharma, and A.. Mahajan, "Age based user Interface in Mobile Operating System", International Journal of Computer Science, Engineering and Applications, vol. 2, no. 2, 2012.

[39] L. G. Motti, N. Vigouroux, and P.. Gorce, "Interaction techniques for older adults using touchscreen devices: a literature review", Proceedings of the 25th Conference on l'Interaction Homme-Machine, pp. 125-135, 2013.

[40] K. Toy, E. O'Meara, R.. Kuber and S. Saulynas, "An Investigation of Ways to Support Older Adults when Using Mobile Interfaces", In iConference 2017 Proceedings, pp. 1-12, 2017.

[41] M. Kobayashi, A. Hiyama, T. Miura, C. Asakawa, M. Hirose, and T. Ifukube, "Elderly User Evaluation of Mobile Touchscreen Interactions", Conference on Human-Computer Interaction, pp. 83-99, 2011.

[42] Google Messages, November 8, 2019, https://play.google.com/store/ apps/details?id=com.google. android.apps.messaging\&hl=en.

[43] Top 15 Mobile Phones Operating System 2019, January 1, 2019, https://www.digitalseoguide.com/technology/top-mobile-phonesoperating-systems-os.

[44] BIG SMS for Seniors, October 4, 2019, https://play.google.com /store/apps/details?id=name.kunes.android.launcher.bigmessages.

[45] Large Launcher, November 11, 2016, https://apkpure.com/largelauncher-big-font-icon/com.tbeasy.largelauncher.

[46] O. S. Pietro, H. Jun and Y. Xin, "Time complexity of evolutionary algorithms for combinatorial optimization: A decade of results", International Journal of Automation and Computing, vol. 4, pp. 218-293, 2007. 